\title{
Research on the Preparation and Characterization of Magnetic Nanoparticles (MNPs) By Chemical Co-precipitation
}

\author{
Guizhong Zhou ${ }^{1, a^{*}}$, Shuo XU ${ }^{1, b}$, Wenqian Li ${ }^{1, c}$, QianYao ${ }^{1, d}$,Dayi Zhang ${ }^{2, e}$ \\ ${ }^{1}$ College of Environment and Safety Engineering, Qingdao University of Science and Technology, \\ Qingdao, 266042, China \\ ${ }^{2}$ Lancaster Environment Centre, Lancaster University, Lancaster LA12YQ, UK \\ *Corresponding author. \\ aemail: zhougz@lqust.edu.cn. eemail: d.zhang@lancaster.ac.uk.
}

Keywords: Ferromagnetic Oxide; Magnetic Nanoparticles(MNPs); coprecipitation; XRD; SEM

\begin{abstract}
The synthesis and characterization of magnetic nanoparticles (MNPs) are attracting more and more attention in recent years. By chemical co-precipitation, $\mathrm{NH}_{3} \cdot \mathrm{H}_{2} \mathrm{O}$ as precipitant, reaction with the mixed solution of $\mathrm{Fe}^{2+}$ and $\mathrm{Fe}^{3+}$, then obtain the nanometer magnetite. The sizesof the products are affected by temperature, stirring speed, the concentration of ferric salt, precipitant concentration, the amount of reactants, and the addition with PAAH which makes its good dispersion. The results showed that the best reaction conditions as follows: reactant ratio is $\mathrm{Fe}^{2+}: \mathrm{Fe}^{3+}: \mathrm{NH}_{3} \cdot \mathrm{H}_{2} \mathrm{O}=1: 1: 10$; precipitant concentration of ammonia is $0.25 \mathrm{~mol} / \mathrm{L}$; iron concentration (the same solution concentration of $\mathrm{Fe}^{2+}$ and $\mathrm{Fe}^{3+}$ ) is $0.5 \mathrm{~mol} / \mathrm{L}$; the temperature control at $25^{\circ} \mathrm{C}$; the stirring speed of $1000 \mathrm{r} / \mathrm{min}$. The XRD and SEM had carried on the preliminary characterization to MNPs analysis which showed the particle size of MNPs is about 20nm. The magnetic properties of MNPs had also tested by VSM.
\end{abstract}

\section{Introduction}

In recent years, with the rapid development of nanotechnology, the ferromagnetic oxide nanoparticles as functional materials are widely used in industrial production and in medical apparatus and instruments. Magnetic nanoparticles (MNPs) are not only widely used in the field of magnetic recording, such as audio tape, high density digital records, data storage, magnetic disk, etc. [1-5], and in special catalytic materials, magnetic pigment, but also has a great purpose in drug synthesis, what is more important in medical equipment, biological medicine uses more and more intensively. The high temperature radio frequency (RF), magnetic resonance imaging, medical diagnosis, cancer therapy and so on is involved in its application [6-9].

At present, the MNPs also more and more applied to the environmental pollution, especially soil restoration and groundwater management. Compared with the conventional iron powder, the size smaller and stronger reactivity of MNPs particle can be suspended in the water pump directly to the location of the polluted. It is helpful to the toxicity of organic pollutants into smaller simple carbohydrates. Heavy metals can also be converted into insoluble form and fixed in the soil [10]. MNPs can improve the structure of activated sludge and conducive to purify water quality[11], its application in the environment will be more and more widely.

Due to the application of magnetic nanoparticles is very broad, and its synthesis and surface modification has become a hot research direction. The preparation methods of magnetic nanoparticles can be roughly classified into physical methods and chemical methods. Physical methods mainly refer to mechanical polishing method; Chemical methods are including hydrothermal method, co-precipitation method, microemulsion method, sol-gel method, nonaqueous solvent synthesis method, high temperature pyrolysis method, etc. [8]. The chemical precipitation method was adopted in this paper, the characterization and the various factors on the properties of nano magnetic ferroferric oxides were explored. 


\section{Experiments}

\section{Reagent and Instruments}

$\mathrm{FeCl}_{3} \cdot 6 \mathrm{H}_{2} \mathrm{O}$ (A.R); $\mathrm{FeSO}_{4} \cdot 7 \mathrm{H}_{2} \mathrm{O}$ (A.R); $\mathrm{NH}_{3} \cdot \mathrm{H}_{2} \mathrm{O}$ (A.R); PAAH (Polyallylamine hydrochloride,10mg/mL) Precision power electric mixer JJ-1 (guohua co., LTD.); Electrothermal blowing GZX-9076 Boxun industrial co., LTD. (Shanghai medical equipment factory); Constant temperature water-bath HH-4 Ziquan instrument co., LTD (Qingdao); Vortex mixing apparatus Scilogex MX-S; Bench centrifuge TGL-16G (Shanghai anting scientific instrument factory); Field emission scanning electron microscope JSM-6700F (Japanese electronics company); X-ray diffraction D/Max-2500/PC (master company in Japan); Vibrating Sample Magnetometer (VSM 7407, Shanghai University)

\section{Experiment Principle}

Chemical coprecipitation method is the process of preparation of ultrafine particles in the solution to form colloid particle coagulation. It can be divided into two stages: the first stage is the formation of crystal nucleus. The second stage is the growth of the crystal (nucleus). And the formation of crystal nucleus speed $\mathrm{v}_{1}$ and crystal growth speed $\mathrm{v}_{2}$ can be expressed by the following two type:

$$
\begin{aligned}
& \mathrm{V}_{1}=\frac{d n}{d t}=k_{1}\left(\frac{c-s}{s}\right) \\
& \mathrm{V}_{2}=k_{2} D(c-s)
\end{aligned}
$$

Among them, the $\boldsymbol{d n} / \boldsymbol{d t}$ is the number of generated crystal nucleus in per time; $\boldsymbol{c}$ is the concentration of the substance (which is the supersaturated concentration); $\mathbf{s}$ is its solubility; so (c-s) is supersaturation; $\boldsymbol{k}_{\mathbf{1}}$ and $\boldsymbol{k}_{\mathbf{2}}$ are the proportional constant; $\boldsymbol{D}$ is the diffusion coefficient of solute molecules. When the $\mathbf{v}_{\mathbf{1}}>\mathbf{v}_{\mathbf{2}}$, generating a large number of crystal nucleus in the solution, and the grain size is small; When $\mathbf{v}_{\mathbf{1}}<\mathbf{v}_{\mathbf{2}}$, generating a small amount of crystal nucleus in the solution, the grain size becomes larger [12].

Using chemical coprecipitation method, mixing the bivalent iron salts solution with trivalent iron salts solution according to certain proportion, then quickly adding a certain percentage of the alkaline precipitant, mixing and reaction immediately after a period of time, centrifugal separation or be powerful magnet separation, after washing, drying, grinding, can get the ferromagnetic oxide nanoparticles. The reaction equation is as follows:

$$
\mathrm{Fe}^{2+}+2 \mathrm{Fe}^{3+}+8 \mathrm{OH}^{-}=\mathrm{Fe}_{3} \mathrm{O}_{4}+4 \mathrm{H}_{2} \mathrm{O}
$$

$\mathrm{Fe}_{3} \mathrm{O}_{4}$ is composite oxide, which can be expressed as $\mathrm{FeO} \cdot \mathrm{Fe}_{2} \mathrm{O}_{3}$. It is transformed by the corresponding hydroxyl. The equation shows that the reaction theory of mole ratio is $\mathrm{Fe}^{2+}: \mathrm{Fe}^{3+}: \mathrm{OH}^{--}$ $=1: 2: 8$. Considering the bivalent iron easy to oxidation, the response of bivalent iron salts can be appropriately excess, recommended in reaction under nitrogen atmosphere.The ratio of iron salt and precipitating agent added, influence precipitation concentration, iron concentration, temperature, stirring speed and other factors on the performance of MNPs had been examined in this study.

\section{Preparation of Ferroferric Oxide MNPs}

The moderate alkaline-- $\mathrm{NH}_{3} \cdot \mathrm{H}_{2} \mathrm{O}$ was adopted as precipitant in this experiment. The bivalent iron salts $\left(\mathrm{FeSO}_{4} \cdot 7 \mathrm{H}_{2} \mathrm{O}\right)$ and trivalent iron salts $\left(\mathrm{FeCl}_{3} \cdot 6 \mathrm{H}_{2} \mathrm{O}\right)$ were added to the three flask to make mixed solution at a certain ratio, then more than $25 \%$ (mass fraction) of ammonia added to the flask, in which the flask pumped in nitrogen starvation, with the blender at a certain speed and in constant temperature water bath. The reaction continued until the solution color change from green to black, and then stirred for 15 minutes ended the reaction. The reaction solution was put in a beaker, under which had a powerful magnets to separate the ferroferric oxide particles. The particles were repeated washing with distilled water several times, put them into the oven to dry for 6 hours under the condition of $60^{\circ} \mathrm{C}$. Then after grinding, Ferroferric Oxide MNPs were obtained at last. 


\section{Results and discussion}

\section{Characterization of MNPs XRD Analyses}

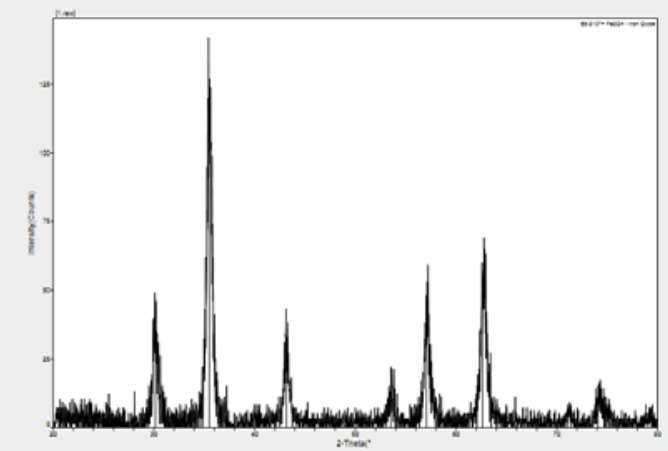

Fig1. XRD of $\mathrm{Fe}_{3} \mathrm{O}_{4}$ nanoparticles at $25^{\circ} \mathrm{C}$

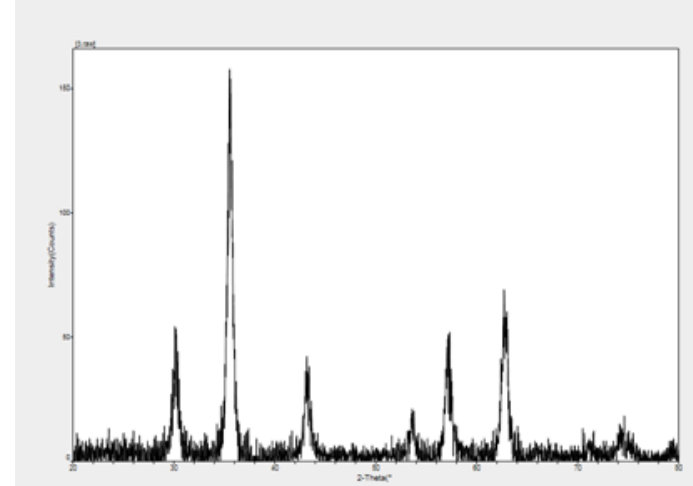

Fig.2. $\mathrm{XRD}$ of $\mathrm{Fe}_{3} \mathrm{O}_{4}$ nanoparticles at $35^{\circ} \mathrm{C}$

From Fig. 1, the particle diameter could be calculated with Scherer's equation, which $\mathrm{D}=17.2 \mathrm{~nm}$. The average particle size was $15.1 \mathrm{~nm}$ after the peak fitting. The average particle size in the Fig.2 was $18.9 n m$ obtained in the same way.

\section{SEM Analyses}

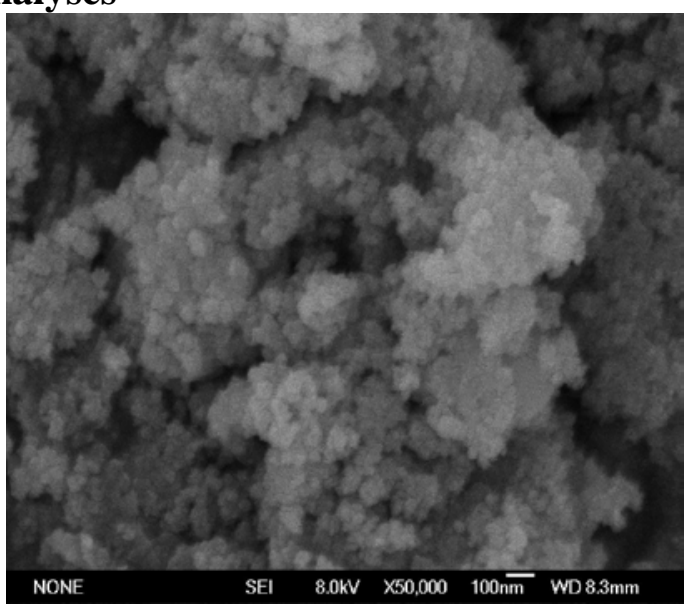

Fig.3. SEM images of the $\mathrm{Fe}_{3} \mathrm{O}_{4}$ nanoparticles

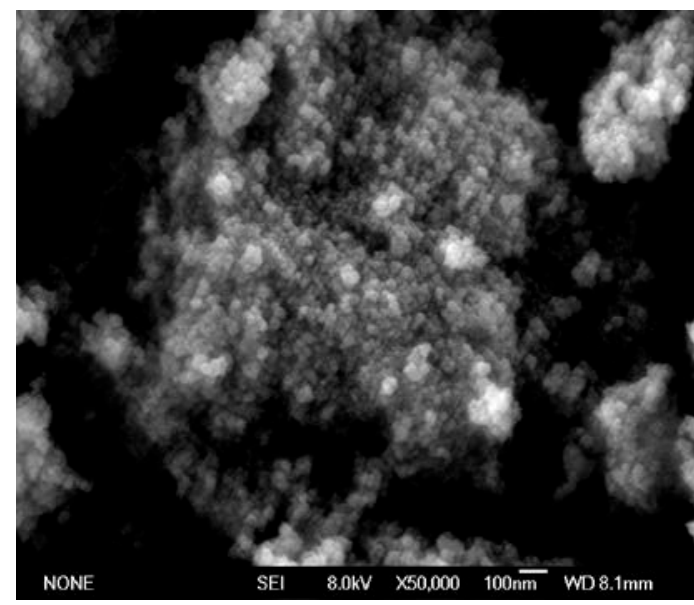

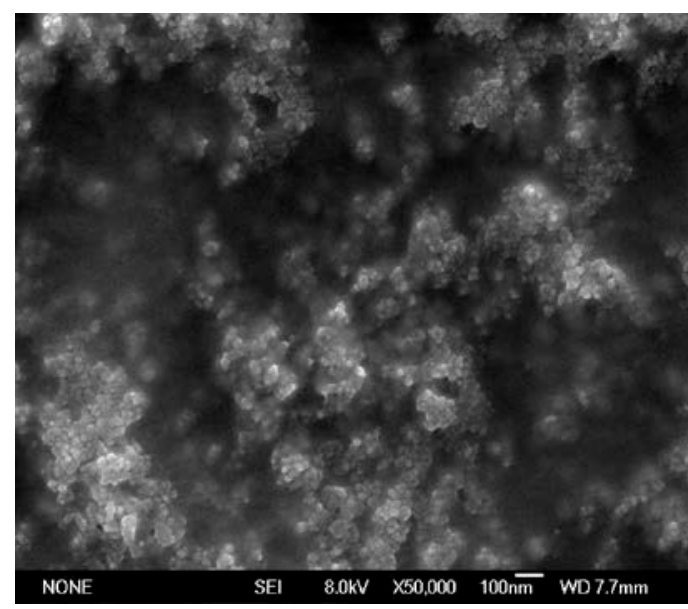

Fig.4. SEM images of the $\mathrm{Fe}_{3} \mathrm{O}_{4}$ nanoparticles obtained with PAAH

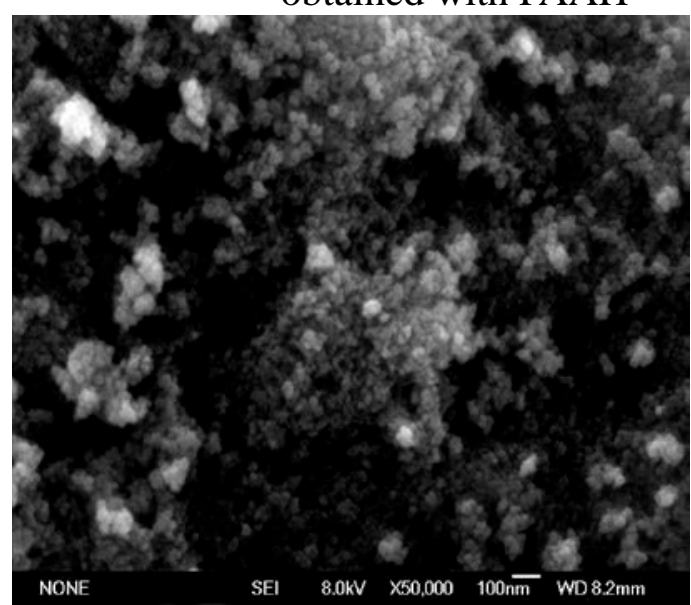

Fig.5. SEM images of the $\mathrm{Fe}_{3} \mathrm{O}_{4}$ nanoparticles obtained with $0.1 \mathrm{~mol} / \mathrm{L}$ and $0.25 \mathrm{~mol} / \mathrm{L} \mathrm{NH}{ }_{3}$ 

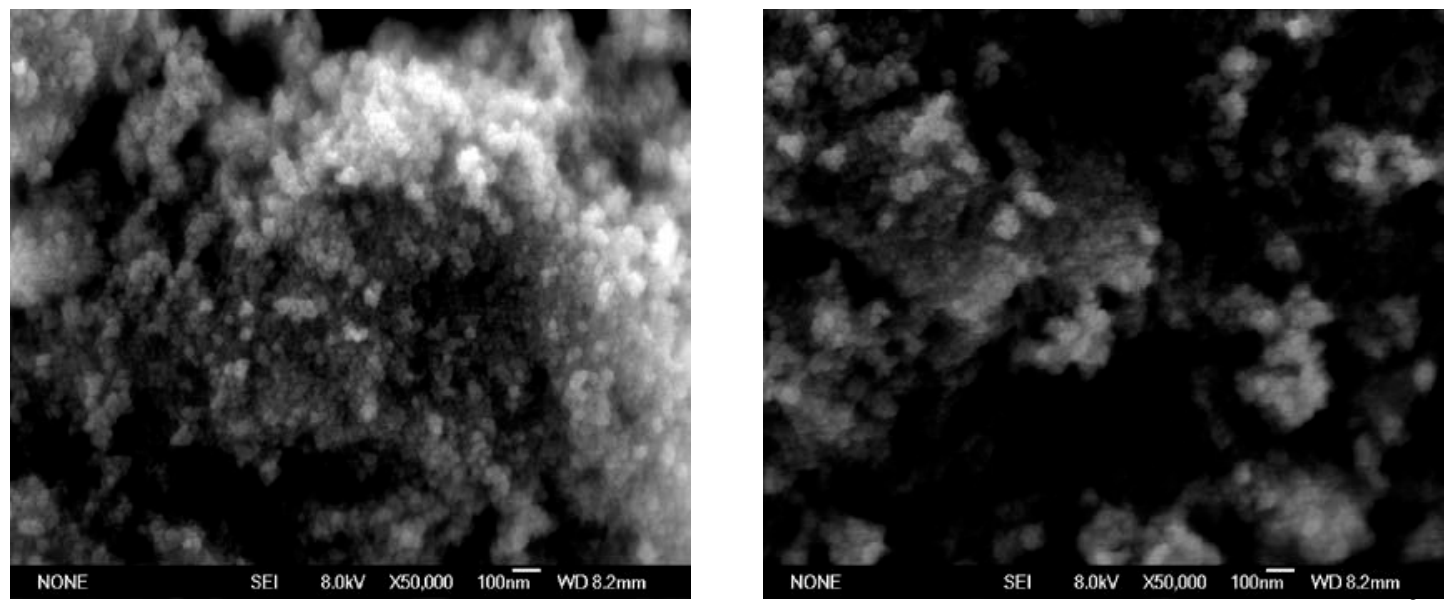

Fig.6. SEM images of the $\mathrm{Fe}_{3} \mathrm{O}_{4}$ nanoparticles obtained with $0.1 \mathrm{~mol} / \mathrm{L}$ and $0.5 \mathrm{~mol} / \mathrm{L} \mathrm{Fe}^{2+}$

From above pictures, ferroferric oxide nanoparticles had mainly spherical structure, within 20nm even size could be found, and XRD calculation tallies the particle size was better. MNPs electron microscope images in Fig. 3 had no dispersing agent and coating agent. MNPs agglomeration was quite serious and difficult to form a good dispersion of the suspension in that situation. Particle dispersion was better, and little change in particle size (remain at around $20 \mathrm{~nm}$ ), when PAAH(10mg/mL) as the dispersant in Fig.4. Fig.5 showed that ammonia concentration changes of MNPs had little effect on particle size; Fig.6 told that the impact of salt concentration change of MNPs particle size was not significantly; as temperature increase, the stirring speed increase MNPs were reunited occur as show.

\section{VSM Analyses}

The hysteresis loops of magnetic $\mathrm{Fe}_{3} \mathrm{O}_{4}$ nanoparticles measured at different factors $(0.1 \mathrm{~mol} / \mathrm{L}$ and $0.25 \mathrm{~mol} / \mathrm{L} \mathrm{NH}_{3} \cdot \mathrm{H}_{2} \mathrm{O}, 0.1 \mathrm{~mol} / \mathrm{L}$ and $0.5 \mathrm{~mol} / \mathrm{L} \mathrm{Fe}{ }^{2+}, 25^{\circ} \mathrm{C}$ and $45^{\circ} \mathrm{C}, 1000 \mathrm{rpm}$ and $\left.2500 \mathrm{rpm}\right)$. The results were shown in figure 7 .
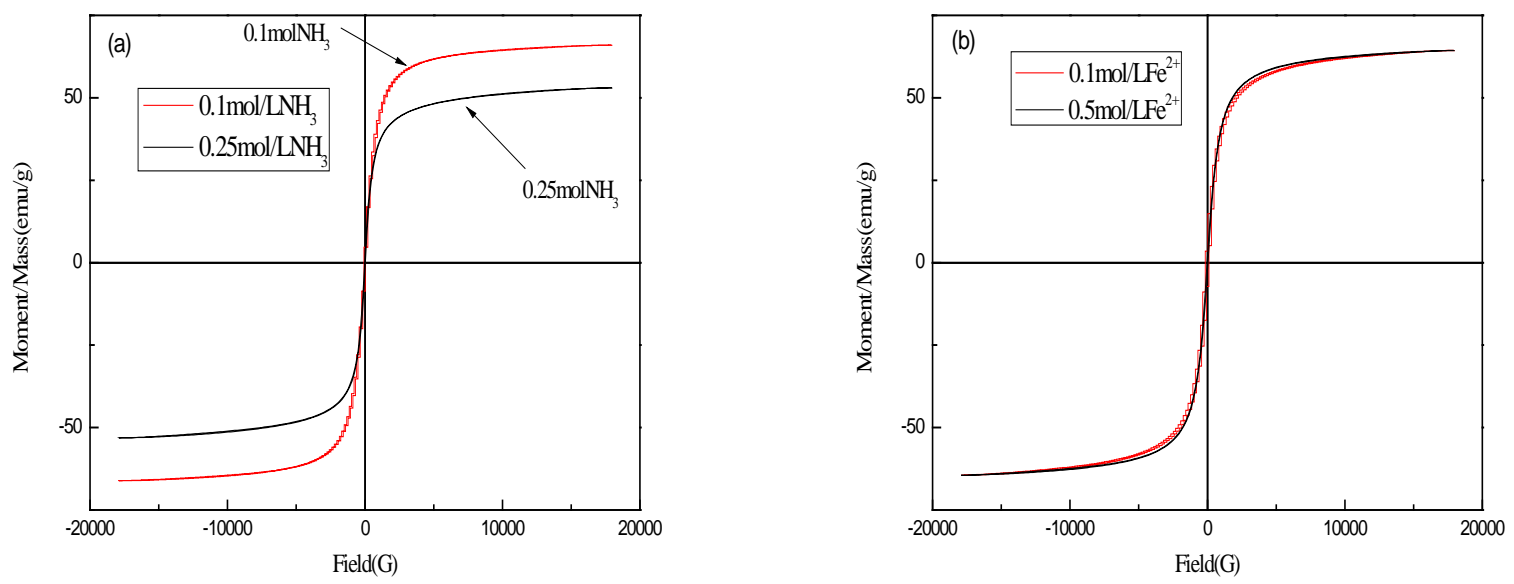

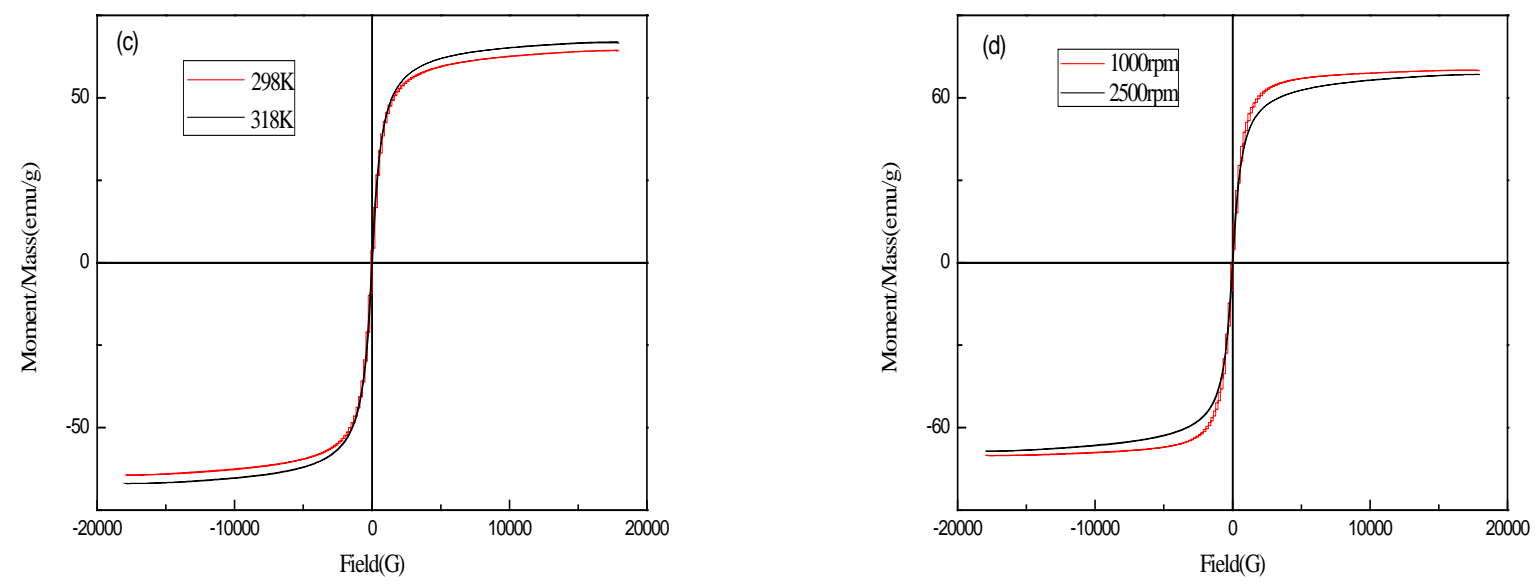

Fig.7. Hysteresis loops of magnetic $\mathrm{Fe}_{3} \mathrm{O}_{4}$ nanoparticles

Saturation magnetization were 65.8881emu/g and 52.9444emu/g, $64.2985 \mathrm{emu} / \mathrm{g}$ and 64.3126 emu/g, $64.2396 \mathrm{emu} / \mathrm{g}$ and $66.6094 \mathrm{emu} / \mathrm{g}, 69.8824 \mathrm{emu} / \mathrm{g}$ and $68.4394 \mathrm{emu} / \mathrm{g} .(\mathrm{a}),(\mathrm{b})$, (c), (d) respectively represent the influence of different factors on the magnetic properties, which had been characterized by paramagnetic, as the magnetic hysteresis curve showed. The concentration of ammonia was the most significant effect on magnetization properties of MNPs from these curves.

The saturation magnetization intensity was dropped down as the increase of ammonia concentration, which was due to the saturation magnetization decreases with the decrease of the crystallinity. Particle size decreases with increased ammonia concentration was consistent; Iron concentration almost had no effect on magnetization properties of MNPs; Temperature and stirring speed had little influence on the magnetization properties of MNPs.

\section{Conclusion}

Magnetic ferroferric oxide MNPs were prepared with chemical coprecipitation preparation method in this paper. The best preparation conditions considering in the study were: additive amount of reactant ratio of $\mathrm{Fe}^{2+}: \mathrm{Fe}^{3+}: \mathrm{NH}_{3} \cdot \mathrm{H}_{2} \mathrm{O}=1: 1: 10$, precipitant concentration of ammonia was $0.25 \mathrm{~mol} / \mathrm{L}$, iron concentration (the same solution concentration of $\mathrm{Fe}^{2+}$ and $\mathrm{Fe}^{3+}$ ) was $0.5 \mathrm{~mol} / \mathrm{L}$, the temperature control was at $25^{\circ} \mathrm{C}$ or so, the stirring speed of was $1000 \mathrm{r} / \mathrm{min}$. In such conditions, particle size of MNPs was stability within 20nm. At the same time, it could be seen that the particle size increased with the increase of temperature. And precipitant concentration of ammonia had little effects on the size and color of the product. Iron concentration should not be less than $0.2 \mathrm{~mol} / \mathrm{L}$; otherwise easily lead to the final product was not pure oxidation. The mixing speed remain above $1000 \mathrm{r} / \mathrm{min}$ was necessary to maintain the small particle size of MNPs.

In addition, the nanoscale magnetic ferroferric oxide easy to reunite, the use of PAAH as the MNPs' dispersant in solution was a good way, and had a little MNPs size change.

The VSM Analyses told that all the MNPs had good magnetic properties. The saturation magnetization intensity was dropped down most significantly as the increase of ammonia concentration in the all concern conditions.

\section{Acknowledgements}

This work was supported by the Shandong Province Natural Science Foundation (Effect of micro-electrolysis pretreatment of salt water on microbial activity) under Grant no.ZR2013EEL008.

\section{References}

[1] Tricot, et al. Process for the preparation of magnetic beads of vinylaromaticpolymers[S]. USP4 
$339337,1982$.

[2] Hiromichi Noguchi, Noriko Yanase, Yasuzo Uchida, et al. Preparation and characterization by thermal analysis of magnetic latex particles[J].Appl Polym Sci.1993,48:1593-1597.

[3] Y.Haik, V.Pai, J.Che. Development of magnetic device for cell separation[J]. Magn Mater.1999,194:254-261.

[4] K.Nakatsuka. Trends of magnetic fluid applications in Japan[J]. Magn Mater, 1993,122:387 394

[5] Richard, et al. Latex of calibrated mono-disperse magnetizable microsphere, process of preparation and use of saidlatexin chemistry orin biology[S].USP5 976 426,1999.

[6]Gholamreza Nabiyouni, Mahdie Julaee, Davood Ghanbari .Room temperature synthesis and magnetic property studies of $\mathrm{Fe}_{3} \mathrm{O}_{4}$ nanoparticles prepared by a simple precipitation method[J].Journal of Industrial and Engineering Chemistry. 2015, 21: 599-603.

[7]J.M.Niu,Z.G.Zheng. Effect of Temperature on $\mathrm{Fe}_{3} \mathrm{O}_{4}$ Magnetic Nanoparticles prepared by Coprecipitation Method[J].Advanced Materials Research Vol .2014,900:172-176.

[8]A. Manikandana, J. Judith Vijaya, J. Arul Marya,L. John Kennedy,A. Dinesh. Structural, optical and magnetic properties of $\mathrm{Fe}_{3} \mathrm{O}_{4}$ nanoparticles prepared by a facile microwave combustion method[J].Journal of Industrial and Engineering Chemistry.2014, 20:2077-2085.

[9] Saeed Kamali, Nesa Shahmiri, José S. Garitaonandia. Effect of mixing tool on magnetic properties of hematite nanoparticles prepared by sol-gel method[J]. Thin Solid Films. 2013,534 : 260-264.

[10]M.A. Abdalla,M.H. Jaafar,Z.A. Al-Othman,S.M. Alfadul,M. Ali Khan.New route for preparation and characterization of magnetite nanoparticles[J].Arabian Journal of Chemistry.2011,4:235-237.

[11]Dayi Zhang,Rawil F.Fakhrullin,Mustafa Özmen,Hui Wang,et al.Functionalization of whole-cell bacterial reporters with magnetic nanoparticles[J].Microbial Biotechnology.2011,4(1):89-97.

[12] Runhua Qin,Wei Jiang,Hongying Liu,Fengsheng Li.Preparation and characterization of nanometer magnetite[J].Chemical Research in Chinese Universities.2003,17:66-68. 